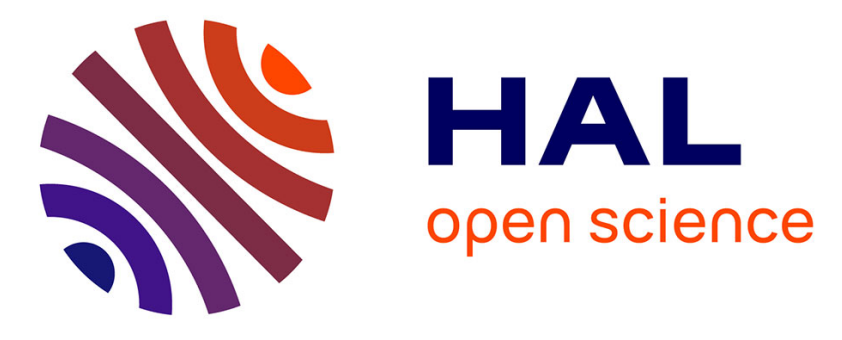

\title{
Quantitative study of open channels by digital holography
}

Alexey Brodoline, Nicolas Verrier, Ludovic Depreater, Didier Felbacq, Michel

Gross

\section{- To cite this version:}

Alexey Brodoline, Nicolas Verrier, Ludovic Depreater, Didier Felbacq, Michel Gross. Quantitative study of open channels by digital holography. Conference on Lasers and Electro-Optics Europe European Quantum Electronics Conference (CLEO/Europe-EQEC), Jun 2017, München, Germany. pp.EG_2_5, 10.1109/cleoe-eqec.2017.8087591 . hal-01927223

\section{HAL Id: hal-01927223 \\ https://hal.science/hal-01927223}

Submitted on 19 Nov 2018

HAL is a multi-disciplinary open access archive for the deposit and dissemination of scientific research documents, whether they are published or not. The documents may come from teaching and research institutions in France or abroad, or from public or private research centers.
L'archive ouverte pluridisciplinaire HAL, est destinée au dépôt et à la diffusion de documents scientifiques de niveau recherche, publiés ou non, émanant des établissements d'enseignement et de recherche français ou étrangers, des laboratoires publics ou privés. 


\title{
Quantitative Study of open channels by digital holography
}

\author{
Alexey Brodoline ${ }^{1}$, Nicolas Verrier ${ }^{2}$, Ludovic Depreater ${ }^{1}$, Didier Felbacq ${ }^{1}$ and Michel Gross ${ }^{{ }^{*}}$ \\ ${ }^{1}$ Laboratoire Charles Coulomb - UMR 5221 CNRS-Université Montpellier Place Eugène Bataillon 34095 Montpellier (FRANCE) \\ ${ }^{2}$ Laboratoire MIPS - EA 2332 IUT de Mulhouse (GEII) 61 rue Albert Camus 68200 Mulhouse (FRANCE) \\ "michel.gross@umontpellier.fr
}

Citation: A. Brodoline, N. Verrier, L. Depreater, D. Felbacq, and M. Gross, "Quantitative Study of open channels by digital holography," in 2017 European Conference on Lasers and Electro-Optics and European Quantum Electronics Conference, (Optical Society of America, 2017), paper EG_2_5.

European Quantum Electronics Conference 2017 : Munich Germany 25-29 June 2017

ISBN: 978-1-5090-6736-7 DOI : 10.1109/CLEOE-EQEC.2017.8087591

From the session Complex Electromagnetic Fields (EG_2)

Open channels are peculiar incidents modes of the optical field that are transmitted by a highly diffusing medium with high efficiency (100\% in the ideal case). The existence of these modes has been predicted by Dorokhov et al. [1] more than 25 years ago. Although many experiments were made to prepare these modes $[2,3]$, the maxima of transmission obtained in experiments, are ever much lower than $100 \%$. To test the theory, we have considered here another Dorokhov's prediction: the average transmission of the modes that sustain the transmitted field must be $\mathrm{T}_{\mathrm{T}}=66 \%$, where $\mathrm{T}_{\mathrm{T}}$ is defined by $N_{2} \mathrm{~T}_{\mathrm{T}}=N_{1} \mathrm{~T}$ (where $\mathrm{T}$ is the averaged transmission of energy, and $N_{1}$ and $N_{2}$ the number of incident and transmitted modes i.e. the size of the incident and transmitted mode basis).
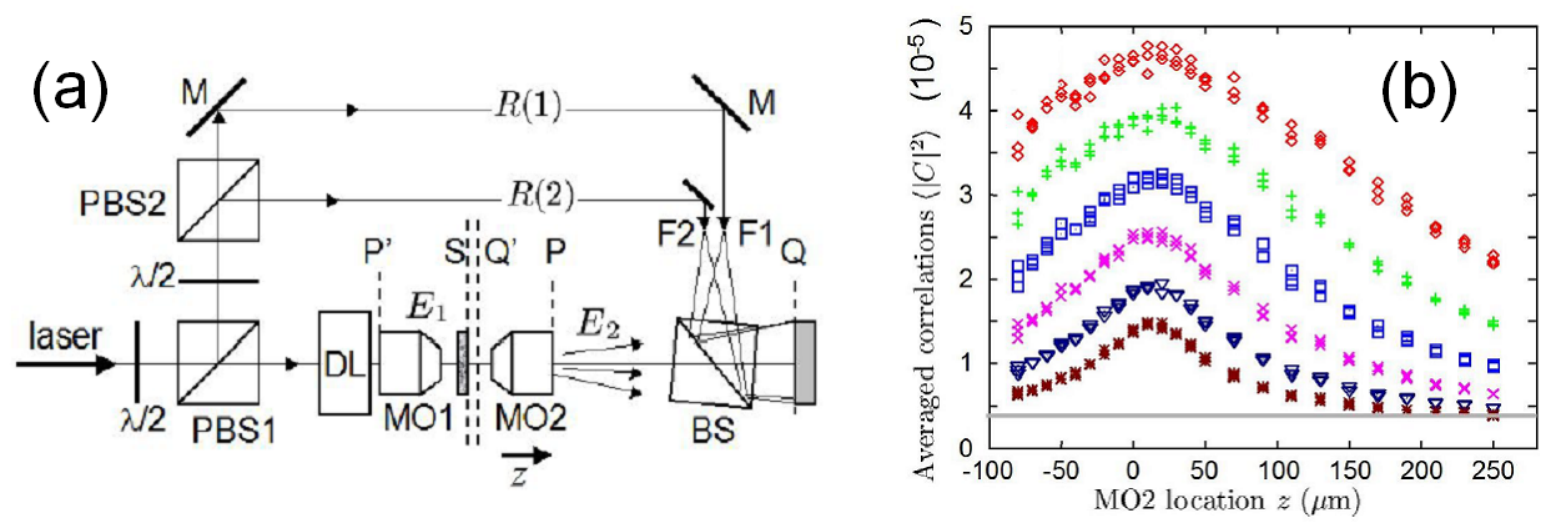

Fig.1 (a) Holographic experimental setup. (b) Residual correlation of the transmitted field. The horizonal axis is SQ'. The sample transverse size is $\mathrm{L}=70 \mu \mathrm{m}$ red, $50 \mu \mathrm{m}$ green, $35 \mu \mathrm{m}$ blue.... The horizontal grey line is the residual correlation expected for $N_{1}=N_{2}$.

To verify this prediction, we have measured $N_{2}$ on a slab sample of $Z_{N} O$ powder (transverse size $\mathrm{L}<=70$ $\mu \mathrm{m}$, thickness $20 \mu \mathrm{m}$ ) [4], by assuming that $N_{1}$ is given by the sample geometry. The experimental setup is seen in Fig. 1(a). The incident fields are random (there are scrambled by a diffusing liquid DL) and digital holography is used to measure the complex transmitted field $E(x, y)$ for the two polarisations. $N_{2}$ is measured by analysing the residual correlations of the transmitted field measured for uncorrelated incident fields.

Since the average transmission is $\mathrm{T}=1 / 25$, we expect $N_{2}=N_{1} / 16$. To get this optimal result, the transverse size of sample L must be infinite and the defocusing SQ' of the microscope objective MO2 must be zero (where $\mathrm{S}$ is the sample outgoing surface and Q' the plane imaged by MO2). Figure 1 (b) shows the residual correlation (which is proportional to $1 / N 2$ ) as a function these two parameters. We get $N_{2}=N_{1} / 12$ without extrapolation, and $N_{2}=N_{1} / 16$ with extrapolation to $\mathrm{L}$ infinite. Here, the open channel effect is huge (factor 16) and the aggreement with the Dorokhov's prediction is excellent.

We acknowledge Labex Numev (convention ANR-10-LABX-20) for funding.

\section{References}

1. O.N. Dorokhov. On the coexistence of localized and extended electronic states in the metallic phase. Solid state communications, 51(6): 381-384, (1984). 
2. Hyeonseung Yu, Timothy R Hillman, Wonshik Choi, Ji Oon Lee, Michael S Feld, Ramachandra R Dasari, and YongKeun Park. Measuring large optical transmission matrices of disordered media. Physical review letters, 111(15):153902, (2013).

3. SM Popoff, A Goetschy, SF Liew, A Douglas Stone, and Hui Cao. Coherent control of total transmission of light through disorder Physical review letters, 112(13), 133903. (2014)

4. Verrier, N., Depraeter, L., Felbacq, D., \& Gross, M. Measuring enhanced optical correlations induced by transmission open channels in a slab geometry. Physical Review B, 93(16), 161114. (2016) 